\title{
A la búsqueda de un régimen jurídico animal
}

Keywords: seres sintientes; derecho animal; legislación

En los últimos años la reflexión del Derecho acerca de los animales, está abriéndose camino en todo el mundo. Prueba de esta afirmación son las modificaciones que el tradicional estatuto jurídico del "animalcosa”, dominante en los países de derecho codificado, ha venido experimentando en algunos países de nuestro entorno más próximo. Es sabido que, desde que Austria introdujo en el Tratado de Propiedad de su Código Civil (ABGB), la modificación de que los animales "no son cosas” y se rigen por leyes especiales, la impronta del cambio tuvo una repercusión inmediata en Alemania, donde se reformó en el mismo sentido el Código Civil (BGB), al igual que, poco más tarde hizo el Código Civil suizo [1]. Por lo tanto, en la década de los 90 se produjo un cambio importante, que vino a poner en cuestión la subsistencia de una categoría aquilatada en el Derecho desde época romana: los animales son cosas en propiedad.

Es cierto que tal cambio (los animales son “no-cosas”), puede ser criticable por parecer una modificación de poca envergadura, poco ambiciosa pues no llega a dar un estatuto jurídico nuevo, ni mejora la condición jurídica de los animales, simplemente respeta la permanencia de los animales dentro de las relaciones de Propiedad, traza un difícil equilibrio jurídico con la negación de que son “cosas” y abre la puerta a que la condición jurídica de los animales se rija por sus propias leyes.

A partir del mencionado cambio, otros sistemas jurídicos han adoptado la misma fórmula negativa ("nocosas”). Entre ellos, cabe citar el libro $5^{\circ}$ del Código Civil catalán (2006), y muy recientemente, como hemos tenido ocasión de dar noticia cumplida en esta web [2], el Código Civil de Chequia. Por lo demás, en Bulgaria se aprobó el 31 de enero de 2008 la Ley de Protección Animal [3], una iniciativa que están siguiendo otros países del Este de Europa. Nos encontramos, pues, a día de hoy, con 5 Códigos civiles europeos que han dado un paso -aún insuficiente- en la búsqueda de una definición jurídica de los animales, que se adapte a lo que la ciencia viene reconociendo desde hace ya bastante tiempo, esto es: que los animales son "seres sintientes” (“sentient beings”). Sólo un texto jurídico, de carácter programático, ha incorporado esta expresión científica de tanta carga expresiva, respetuosa con la condición de los animales como seres a los que nos une nuestra capacidad de sentir y de sufrir. Me refiero al Tratado de Lisboa [4], que no es -aunque impropiamente así se le denomine-, una Constitución para Europa, pero es el marco que los Estados Miembros hemos aceptado como inspirador de nuestras propias leyes.

El empleo de la expresión "seres sintientes”, como estándar regulador del bienestar animal, sí se usa en muchos textos legales de la UE -sobre todo de los últimos años-, gracias a la infatigable labor de la Comisión Europea, a través principalmente de la DG SANCO [5]. En este terreno del Bienestar Animal, sí puede decirse que se han conseguido grandes avances. Sólo basta recordar la normativa relativa a la eliminación de la cría de gallinas en batería (“battery cages”), que en España está revolucionando literalmente el sector avícola y los hábitos de los consumidores, que empiezan a examinar con interés la numeración de los huevos, para saber si las gallinas de los que proceden han tenido una crianza respetuosa con sus necesidades e intereses [6]. Dicho coloquialmente, si los huevos proceden o no de gallinas camperas.

A lo que me refiero es a la incorporación del trabajo de la ciencia veterinaria a la ciencia jurídica. Es decir, a la necesidad de que los textos jurídicos, sobre todo aquellos sobre los que pivota todo el sistema normativo y la aplicación judicial de las normas, adopten en su redactado el uso de categorías que sitúen a los animales dentro de un contexto más acorde con su condición de seres sintientes, fuera, por lo tanto, 
del campo de las cosas y de las estrictas relaciones de Propiedad. El trabajo de veterinarios y de juristas debería de experimentar un acercamiento, que redundaría en la mejora de la condición de vida de los animales. Sólo así podríamos abordar, desde bases sólidas, los cambios que el sistema jurídico, en relación con los animales, precisa hoy más que nunca.

Parte de nuestra labor, en los próximos años radica en crear puentes de aproximación. Compartimos un mismo interés, los animales, pero hay que eliminar algunos de los obstáculos que, hasta ahora, han venido manteniéndonos alejados. Enuncio sólo uno, como muestra del recorrido que convendría iniciar, que es el esfuerzo por hacer del lenguaje jurídico -un lenguaje, desde luego, técnico-, un instrumento de entendimiento, más claro, más preciso, más abierto.

LA EDITORA

Teresa Giménez-Candela Catedrática de Derecho Romano Animal Law Profesor Universitat Autònoma de Barcelona

[1] Austria: ABGB, 1986; Alemania: BGB, 1990; Suiza: BGB, 2000.

[2] MÜLEROVÁ, Hana, Animals Finally above Objects and stricter Criminalization of Cruelty in Czech Legislation, en DA, marzo 2012

[3] Vid. link externo

[4] Vid. link externo

[5] Vid. $\underline{\text { link externo }}$

[6] Vid. link externo 